\title{
Measles at the present stage
}

\author{
Aygerim Zhuzzhasarova, Dinagul Bayesheva, Alena Altynbekova, Bayan Turdalina, Aliya Seidullayeva, Aitolkyn \\ Mynzhanova, Almagul Kushugulova
}

${ }^{1}$ Astana Medical University, Nur-Sultan, Kazakhstan

${ }^{2}$ Multidisciplinary city Hospital No ${ }^{3}$, Nur-Sultan, Kazakhstan

${ }^{3}$ Center of Life Sciences, Nazarbayev University, Nur-Sultan, Kazakhstan

Received: 2021-08-31.

Accepted: 2021-11-23

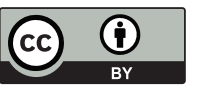

This work is licensed under a Creative Commons Attribution 4.0 International License

J Clin Med Kaz 2021; 18(6):25-31

Corresponding author:

Aygerim Zhuzzhasarova.

E-mail: zhuzzhasarova.a87@gmail.com;

ORCID: 0000-0001-6556-4489

\begin{abstract}
Measles is an acute infectious disease characterized by a combination of catarrhal symptoms and specific exanthema. This is a highly contagious, potentially fatal infection with an airborne transmission mechanism. A distinctive feature of the pathogen of which is the ability to cause prolonged post-infectious immunosuppression. Fever in combination with one of the following manifestations: cough, runny nose, conjunctivitis are the first clinical manifestations of the disease. The Belsky-Filatov-Koplik spots are specific rashes on the mucous membrane of the cheeks, allowing to establish a diagnosis even before the appearance of exanthema. The rash usually appears 3-4 days after the onset of an increase in body temperature and is characterized by a gradual rash, initially occurs on the face and behind the ears, which is associated with the peak of the clinical picture. Measles is characterized by a polysystemic lesion, with a predominant involvement in the pathological process of the central and respiratory systems of the body, while pneumonia is one of the most frequent complications that lead to a fatal outcome. In the treatment of measles, supportive therapy, correction of dehydration and nutrient deficiency, as well as treatment of secondary bacterial infections and providing the body with vitamin A are of great importance. It is important to note that measles has lifelong immunity after an infection or vaccination, while vaccination against measles plays a crucial role in its elimination. Previously, it was believed that measles is on the verge of eradication, but its outbreaks in Europe at the present stage have led to the return and spread of this infection. Measles remains the leading cause of global child mortality in the world, as children from developing countries are most susceptible to this disease. About 45 million new cases of measles are registered annually in the world, among which almost a million people die.
\end{abstract}

Key words: measles, children, clinic, diagnosis, treatment, prevention

\section{Modern views of measles in children}

Measles is a viral disease with a high potential for spread and the development of complications in about $30 \%$ of cases, the main contingent of patients are children under the age of 5 years, mainly with a nutritional deficiency and a weakened immune system. At the present stage, measles remains a significant morbidity and remains a significant cause of death worldwide, especially among young children, due to its widespread spread, even despite the availability of a safe and effective vaccine [1-7].

According to the World Health Organization, it was found that in 2013, about 145,700 people died from measles, most of them children, while about $95 \%$ of the deaths occurred in Africa and Asia [8-10].

The global measles burden exceeded 9.7 million cases in 2015. Of these, 254,928 cases were reported in six WHO regions, while 134,200 (95\% CI=74,400-353,600) people died from this infection 16. 27,086 (88\%) of these cases were reported in 4 countries: Kyrgyzstan-17,779 (58\%), Bosnia and Herzegovina-4,583 (15\%), Germany-2,383 $(8 \%)$ and Kazakhstan-2,341 (8\%) [11,12].

Measles is a potentially liquidable disease, since the reservoir is exclusively a person. Safe, effective vaccines, as well as sensitive and specific laboratory diagnostic tests, have been developed and are widely used today.

The possibility of eliminating measles is due to the formation of lifelong immunity after an infection, the presence of a single antigenic variant of the measles virus worldwide, the absence of other than human reservoirs of the virus in nature, the pronounced manifestation of clinical forms of infection and the availability of effective live vaccines [13]. The World Health Organization (WHO) recommends a two-dose vaccination policy, with the first dose administered during the first year of life, and coverage 
should be maintained at a level of at least $90-95 \%$ in order to interrupt the chain of transmission of the disease [14]. In 2015, measles outbreaks were registered in all 16 regions of the country in Kazakhstan. From January 1, 2015 to January 30, 2016, 2,679 suspected cases of measles were detected. The incidence of measles was recorded in people aged $20-29$ years, $31 \%(n=719)$; adults aged 30 years and older, $26 \%(n=615)$; children under the age of one year, $25 \%(\mathrm{n}=576)$; adolescents and young people aged $15-19$ years, $13 \%(n=300)$. The registered incidence was the highest among people over 14 years of age, $70 \%(n=1634)$ [15].

The possibility of eradicating measles infection is due to the formation of lifelong immunity after infection, the presence of the only antigenic variant of the measles virus worldwide, the absence of other than human virus reservoirs in nature, the pronounced manifestation of clinical forms of infection and the availability of effective live vaccines [13]. The World Health Organization (WHO) recommends vaccination in two doses, with the first dose administered during the first year of a child's life, and vaccination coverage should be maintained at a level of at least $90-95 \%$ in order to interrupt the chain of transmission of the disease $[14,15]$.

In Kazakhstan, measles outbreaks were registered in all 16 regions of the country in 2015. From January 1, 2015 to January 30, 2016, 2,679 suspected cases of measles were detected. The incidence of measles was recorded in people aged 20-29 years, $31 \%(n=719)$; adults aged 30 years and older, $26 \%(n=615)$; children under the age of one year, $25 \%(n=576)$; adolescents and young people aged $15-19$ years, $13 \%(n=300)$. At the same time, the incidence was highest among people over 14 years of age, $70 \%(n=1634)$.

Thus, the fact remains relevant that measles is dangerous at the present stage. It should be noted that the most highly effective and affordable vaccines (live weakened measles vaccines) provide $97 \%$ protection at two doses administered at the age of 12 to 15 months and from 4 to 6 years, with proven safety indicators [16].

According to the latest WHO data, since 2000, measles vaccination has prevented about 21 million deaths worldwide. Despite this, the set global goals were not achieved and the risk of an increase in the incidence of measles by $31 \%$ of the number of cases registered worldwide between 2016 and 2017 remained. The World Health Organization (WHO) reported 117,075 cases of measles and 1,205 deaths in Madagascar observed between the beginning of October 2018 and the beginning of April 2019. In Europe, the number of registered cases in 2018 increased three times compared to 2017 and 15 times compared to 2016. In addition, endemic measles has been reported in several European countries where the elimination of this infection was previously achieved. In the WHO European Region, from January 1 to October 30, 2018, this figure was 53,201. Of these, $89 \%$ of all cases were registered in nine countries, such as: Ukraine-66\% (n $=35,120)$; Serbia-9.5\% $(n=5,057)$; France-5\% $(n=2,787$; $)$, Italy $(n=2,373 ; 4.5 \%)$, Greece $(n=2,192 ; 4 \%)$, the Russian Federation $(n=1822 ; 3 \%)$, Georgia $(n=1502 ; 3 \%)$, Albania $(n=1405 ; 3 \%)$ and Romania $(n=943 ; 2 \%)$. The maximum increase in the incidence is in April and May, such an increase corresponds to the literature data characterizing the seasonality of measles $[16,17]$.

Monitoring of the disease in the Republic of Kazakhstan indicates that the incidence of measles from November 2018 to December 30, 2019, amounted to 13,873 cases, of which $71.2 \%$ $(n=9875)$ were children aged 6 months to 14 years.
Figure 1 - Measles incidence in 2018 and 2019

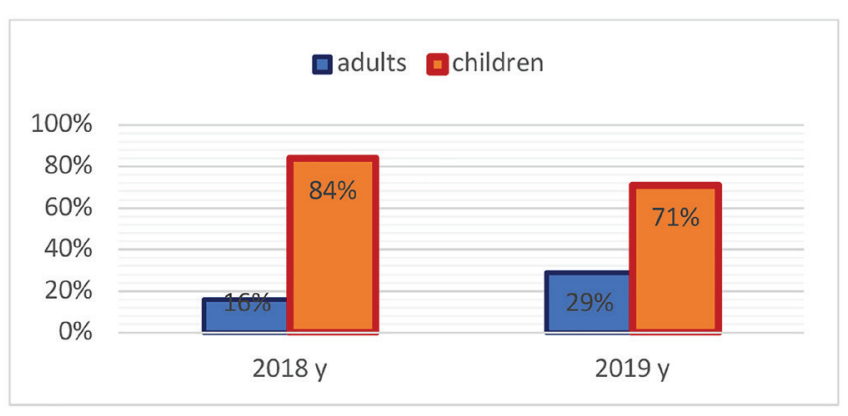

As shown in Figure 1, the total number of cases of measles in the Republic of Kazakhstan in 2018 was 576 cases, of which $84 \%$ were children, $16 \%$ were adults. In 2019 , the total number of cases of measles increased 23 times compared to 2018 and amounted to 13,297 cases. Changes in the age structure are noteworthy, so in 2019 the number of sick children decreased from $84 \%$ to $-71 \%$, but the incidence rates in adults increased from $16 \%$ to $-29 \%$ (Figure 1). The incidence took on an outbreak character in 4 regions of the country, where the number of cases exceeded 1000 patients: Nur-Sultan - 22.9\% $(n=3181)$, in Shymkent - 22.3\% ( $n=3095)$, in Mangystau - 10.3\% ( $=1428)$ and in Turkestan region - 8\% $(n=1110)$. Regions where the number of measles cases ranged from 200 to 1000: Atyrau $(n=775)$, Almaty $(n=617)$, Kyzylorda $(n=535)$, Karaganda $(n=364)$, Zhambyl $(n=433)$, Akmola $(n=312)$, Aktobe $(n=283)$, North Kazakhstan $(n=280)$, Pavlodar $(n=208)$ regions and Almaty ( $n=850)$, up to 200 cases of the disease were registered in Kostanay ( $\mathrm{n}=193)$, as well as in West Kazakhstan $(\mathrm{n}=122)$ and East Kazakhstan $(n=87)$ regions.

Given the high contagiousness of the virus (98-99\%), almost complete vaccination coverage of the population is required to prevent epidemic outbreaks (collective immunity up to $95 \%$ ). However, every year there are increasing cases of refusal of vaccination, which are associated with misconceptions about the safety of the vaccine, especially those that have arisen as a result of repeatedly refuted claims about the link between the vaccine and autism. In addition, some people reject vaccination for religious reasons. A significant reason for medical withdrawal from vaccination may be severe immunosuppression [18].

Unlike many infectious diseases, measles is primarily a public health problem with a clear scientific solution. Every complication or death associated with measles was a preventable tragedy that could have been avoided with timely vaccination. The increase in the incidence of measles at the present stage in the countries of Europe and the CIS, including in our republic, observed in 2017-2019, is a big step back, so today there is a need for a detailed study of the features of the epidemic process of measles to assess the effectiveness of measures taken, substantiate new directions for improving the system of epidemiological surveillance, which will allow to justify a set of measures differentiated in accordance with the conditions of a certain area.

\section{Etiology and clinical manifestations of measles in children}

The causative agent of measles is a virus that belongs to the genus Morbillivirus, the family Paramyxoviridae [18,19] it has a spherical shape and a diameter of 100 to $200 \mathrm{~nm}$ [20-22].

Transmission of the infection occurs from a sick person, including with an atypical form of measles [23]. The virus is 
transmitted by airborne droplets, which persists in the open air for up to 2 hours. The infection rate is $98-99 \%$ [24].

The genetic characteristics of the measles virus are determined by eight classes (A-H), which are divided into 24 genotypes. 20 group A viruses were distributed mainly in China, the United States, Russia and Argentina. The group of viruses $\mathrm{B}$ and $\mathrm{C}$ circulates most often in Japan, South Africa and the Philippines. Viruses of group D and E are registered mainly in Western Europe. Group F viruses are found in Africa. Group $\mathrm{G}$ viruses are circulating in Canada, Malaysia and Indonesia. Group H viruses were detected in China, Japan and Korea [24]. Genotypes of groups B, D and H were registered in Kazakhstan in the period 2010-2019. In the period from November 2018 to March 2019, there was a circulation of D8 and B3 strains (Figure 2), where the Dublin and Kabul genetic lines were established in the B3 genotype, which were characterized by high aggressiveness, pathogenicity and contagiousness.

Figure 2 - Diversity of wild-type measles virus genotypes in the Republic of Kazakhstan, 2010-2019

\begin{tabular}{|c|c|c|c|c|c|c|c|c|c|c|}
\hline \multicolumn{11}{|c|}{$\begin{array}{l}\text { Diversity of wild-type measles virus genotypes in the Republic of Kazakhstan, } \\
2010-2019\end{array}$} \\
\hline Genotype & 2010 & \begin{tabular}{|l|}
2011 \\
\end{tabular} & 2012 & 2013 & 2014 & 2015 & 2016 & 2017 & 2018 & 2019 \\
\hline \multicolumn{11}{|l|}{ D4 } \\
\hline \multicolumn{11}{|l|}{ D8 } \\
\hline B3 & & & & & & & & & & \\
\hline $\mathrm{Hl}$ & & & & & & & & & & \\
\hline
\end{tabular}

Measles does not have gender selectivity, but literature data show that male children are mostly more likely to get sick [25]. Among the main causes of infection are contacts with sick people with fever and respiratory symptoms from areas endemic to measles, immunodeficiency conditions, insufficient nutrition and vitamin A deficiency, as well as the presence of an unfavorable premorbid background [26-33].

The incubation period of measles in general is from 7 to 21 days, on average it is 13-14 days from the moment of contact [34]. The prodromal period lasts from 2 to 4 days. Then comes the period of peak or catarrhal period of the disease, which is characterized by an increase in body temperature, a decrease in appetite, general weakness and the so-called triad of symptoms: runny nose, barking cough and conjunctivitis. Before the appearance of a rash on the mucous membrane of the cheeks, opposite the molars, an enanthema appears - these are the Belsky-Filatov-Koplik spots, which are a pathognomonic symptom of measles in the prodromal period. However, these spots are present only in $60-70 \%$ of patients and usually persist from 12 to 72 hours [35].

The appearance of an exanthema is possible in several ways: in the form of erythema, spots and papules that initially appear on the face, around the hairline, on the sides of the neck and behind the ears $[27,36,37]$. When spreading to the lower extremities, the rash merges in places [38,39-42]. (Fig. 3) More intensively rashes are located in the shoulder area [40,42]. The palms of the hands and the soles of the feet are almost always free of rash $[21,42]$. The rash period lasts from 5 to 10 days, then the rash disappears in the same order in which it appearsm[41,43]. As the rash disappears, there is pigmentation with slight peeling $[21,42]$. At the same time, there is a constant cough that persists for several weeks. Patients may also experience pain in the throat, abdomen, cervical lymphadenopathy and, less often, splenomegaly [42].
Figure 3 - Measles in a child of 12 months, the 6 th day of the disease.

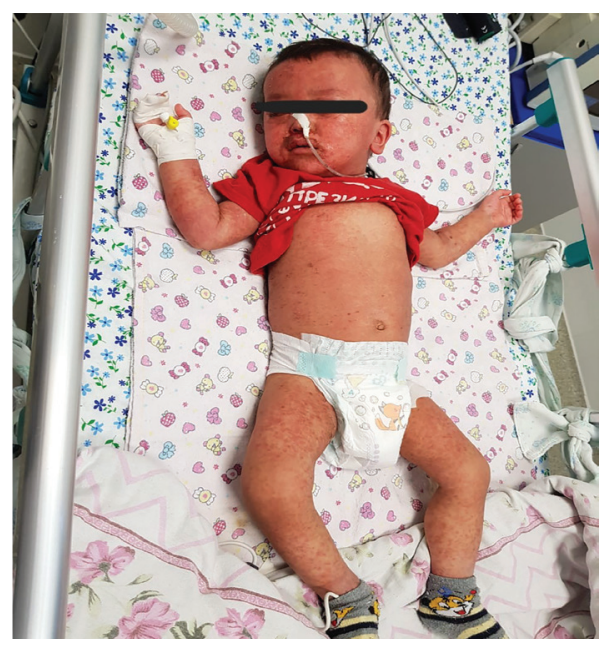

Mild atypical forms of measles include abortive, mitiged, erased and subclinical.

A mild course of measles is observed in people with already existing, but not fully formed immunity from measles, previous contact with the measles virus, transplacental transmission of antibodies against measles or receiving intravenous immunoglobulin [44]. Such patients have a longer incubation period, but lighter and less characteristic clinical manifestations, with a rapid regression of existing symptoms. It should be noted that patients with this form of infection are less contagious [43].

Atypical measles is registered among children vaccinated with the measles vaccine of the killed virus, who were subsequently exposed to the wild-type measles virus. In the period from 1963 to 1967 , the vaccine with the killed measles virus was used in the United States, it increased the sensitivity of people to the antigens of the measles virus, but did not provide full protection. The complaints characteristic of atypical measles are headache and prolonged fever. The rash is usually maculopapular, but it can have a vesicular or petechial character, with a bluish tinge, starting on the distal parts of the extremities (including the palms of the hands and the soles of the feet) and spreading throughout the body. As a complication, severe pneumonia often develops, bilateral infiltrates and intrathoracic lymphadenopathy are characteristic [42]. There may be swelling of the hands and feet, paresthesia or hyperesthesia and hepatosplenomegaly [44]. Atypical measles is considered not contagious [45]. Complications after atypical measles occur in about $10-40 \%$ of patients, mainly in young children, the elderly, pregnant women, patients with malnutrition and immunodeficiency conditions [45].

\section{A complication of measles}

Every fifth patient who has had measles has a risk of complications, which are most often observed in children under the age of 5 years and adults over 20 years. The most common complications of measles occur as a result of immunosuppression and the layering of secondary bacterial flora.

Measles pneumonia is the cause of death in $60 \%$ of cases [20]. It can develop due to the action of the measles virus itself (Hecht's giant cell pneumonia), the layering of secondary viral (adenovirus, herpes simplex virus) or bacterial flora (Streptococcus pneumonia, staphylococcus aureus) [46]. Among the pathology from the ENT organs, complications may occur in the form of the development of otitis media, otosclerosis, 
tonsillitis, sinusitis, laryngotracheobronchitis ("cinnamon croup"), bronchitis [47,48]. Gastrointestinal complications include gastroenteritis, gingivostomatitis, mesenteric lymphadenitis, hepatitis, pancreatitis and appendicitis [49]. Among ophthalmic complications, keratoconjunctivitis is observed, leading to blindness, especially in people with vitamin A deficiency and corneal ulcers. Hematological complications are most often thrombocytopenia and disseminated intravascular coagulopathy. Cardiac complications manifest themselves in the form of pericarditis and carditis [42]. Renal complications lead to glomerulonephritis and acute renal failure [50]. Among neurological complications, febrile convulsions, primary measles encephalitis, acute postinfectious encephalomyelitis, subacute sclerosing panencephalitis are observed [51].

The most severe complication of measles is measles encephalitis. Primary measles encephalitis develops in about one in 1000 measles patients, usually on the 5th day of the rash. At the same time, about $10 \%$ of cases end fatally. Acute postinfectious encephalomyelitis is an autoimmune demyelinating disease that occurs in about one in 1000 measles patients and manifests itself during the recovery period within 2 weeks after the rash.

During pregnancy, measles is particularly dangerous because of the increased risk of spontaneous abortion, premature birth, as well as low fetal body weight at birth, intrauterine death or stillbirth. Since a woman's immunity decreases during pregnancy, infection can lead to a fatal outcome [51].

\section{Diagnosis and differential diagnosis}

The most common confirmation of measles is carried out by a laboratory method based on a positive serological study for antibodies to immunoglobulin $\mathrm{M}$ (IgM) to measles with a fourfold or more increase in the titer of specific IgG in dynamics, isolation of the virus from cultures of mononuclear cells of blood, urine, smears from the conjunctiva or nasopharynx and detection of measles virus RNA using reverse transcriptase polymerase chain reaction (RT-PCR) in blood samples, a smear from the pharynx and nasopharynx or urine [51]. Unfortunately, measlesspecific IgM antibodies can be detected only 4 or more days after the rash appears, which can lead to false negative results if the examination is carried out earlier. Approximately $75 \%$ of patients with measles-specific IgM antibodies are detected within the first 72 hours after the rash appears, but almost all affected children will have measles-specific IgM detected 96 hours after the rash appears. In addition, false positive results can sometimes occur in patients with infectious mononucleosis, rubella, parvovirus infection B19 and rheumatological diseases. Testing of measles virus RNA using RT-PCR is more specific and gives a positive result before the characteristic IgM antibodies to measles appear, and allows identifying the genotype [52].

\section{Observation}

The clinical picture of measles, depending on the seasonality and geographical location, can simulate the manifestations of other viral diseases. It should be emphasized that $\mathrm{MeV}$ infection in people with weakened immunity may not cause the typical symptoms of measles, while often causing severe outcomes of the disease, with the development of pneumonia [53]. Virological surveillance data show a decrease in the overall genetic diversity of measles, since the number of genotypes in the examined patients decreased [54]. Sequencing of larger fragments of the $\mathrm{MeV}$ genome makes it possible to increase the resolution of $\mathrm{MeV}$ transmission routes, including the difference between several import sources of the same genotype and jointly circulating lines in countries with an endemic virus. Areas of interest for extended sequencing include the non-coding region between the matrix (M) and F genes, as well as the entire genome, which can be sequenced by Sanger methods or next-generation methods $[55,56]$. The information obtained from MF-NCR provides phylogenetic trees with a topology similar to that obtained by sequencing the entire genome, demonstrating that this region is useful for improving molecular surveillance of measles [56-58].

\section{Treatment}

In our country, the treatment of children with measles is carried out in accordance with the Clinical Protocol "Diagnosis and treatment of measles in children" of the Republic of Kazakhstan №. 4 of June 9, 2016. The basis is symptomatic therapy, which includes the use of antipyretics, vitamins, preventive measures, proper and enhanced nutrition [44]. In the case of the addition of secondary bacterial flora, treatment is carried out with appropriate antibiotics [44]. According to the 2017 Cochrane Systematic Review, in the treatment of patients with measles, vitamin A should be added orally once a day for 2 consecutive days in age-related doses (50,000 IU, 100,000 IU and 200,000 IU for infants $<6$ months, infants aged 6 to 11 months and children older than 12 months, respectively), which is associated with a significant reduction in mortality and morbidity in children [49].

It should be noted that there is no specific antiviral therapy for measles patients. Although in vitro studies have shown that the measles virus is sensitive to ribavirin [36,59], however, its clinical efficacy and safety profile were not evaluated in any randomized controlled trial.

\section{Prevention. Active immunization}

Today, measles remains one of the causes of morbidity and mortality of children worldwide, especially in developing countries [60]. Universal immunization of children and vaccination of all susceptible patients, including children aged 6-11 months who are at a higher risk of contracting measles: travelers to endemic areas, high school and college students, medical personnel and those who are in the regions of the measles outbreak with the measles vaccine $[27,43]$ are recommended. The only measles vaccine currently in use contains live attenuated measles strains that multiply in the host body, causing both humoral and cellular immunity [36, 40]. To eliminate measles, vaccination coverage of the population should be more than $93 \%[36,40]$. It should be noted that a dose of measles vaccine administered at the age of 1 year or older provides protection against measles from $93 \%$ to $95 \%$, while two doses administered at appropriate intervals are almost $100 \%$ effective [22] a vaccine administered at the age of 9 months provides protection only by $85 \% 54$. Children who received one dose of the measles vaccine before the age of 12 months should receive two additional doses at intervals of at least 28 days after 12 months, since doses administered before 12 months should not be considered valid [52].

The measles vaccine can be administered as a single component (for example, in Russia and some African countries), but more often they are administered in combination with mumps and rubella (MMR) and the measles-mumps-rubella-chickenpox vaccine. The vaccine against measles, mumps, rubella and chickenpox has the same immunogenicity and safety profiles as the CCP vaccine, except that the relative risk of febrile seizures is doubled [52]. 
At the present stage, scientists in many countries are studying alternative methods of immunization to determine the possibility of overcoming the overwhelming effect of maternal antibodies, for the immunization of infants at an earlier age, especially in highly endemic regions [19]. Alternative routes are respiratory and intradermal vaccination using microneedles or disposable jet injectors without needles with cartridges, are also being considered in order to exclude the use of sharp objects that are currently injected subcutaneously $[23,26]$.

The respiratory measles vaccine has been studied for the past 30 years, and in connection with this, the WHO Aerosol Medicines project was created to license a single respiratory method of delivering the measles vaccine. Understanding the average volume of an inhaled vaccine delivered deep into the lungs is important for determining the dose received during aerosolization. Studies show that an effective immune response occurs when the vaccine reaches the deep layers of the lungs, for this, the particles in aerosol form must have a size of $<5$ microns [27].

Reactions to the vaccine occur on average 5-12 days after vaccination, mainly manifested in the form of fever, rash and arthralgia [56]. Contraindications for vaccination are primarily hypersensitivity to any component of the vaccine, including gelatin and neomycin; a confirmed anaphylactic reaction to a previous measles vaccine in the anamnesis, cellular immunodeficiency, moderate or severe disease in the acute period, any febrile disease, pregnancy [61]. Measles vaccination should be postponed for those who have recently taken high doses of corticosteroids, immunoglobulins or blood products [58].

\section{Conclusion}

An increase in measles disease in the Republic of Kazakhstan for 2018-2019 has been registered. The majority of cases occur in children under 14 years of age $73 \%(n=10189)$. Measles at the present stage was accompanied with formidable complications, such as pneumonia, carditis, ARDS, etc. Thus, to eliminate measles among the population, universal immunization of children and vaccination of all susceptible people with an anti-measles vaccine is recommended. Immunization is the responsibility of society, the ultimate goal of which is the complete elimination and eradication of measles.

Disclosures: There is no conflict of interest for all authors.

\section{Acknowledgements: None.}

Funding: None.

\section{References}

1. Schoini P, Karampitsakos T, Avdikou M, Athanasopoulou A, Tsoukalas G, Tzouvelekis A. Measles pneumonitis. Adv Respir Med. 2019;87(1):63-67. doi: 10.5603/ARM.a2019.0010.

2. Imdad A, Mayo-Wilson E, Herzer K, Bhutta ZA. Vitamin A supplementation for preventing morbidity and mortality in children from six months to five years of age. Cochrane Database Syst Rev. 2017;3(3):CD008524. doi: 10.1002/14651858.CD008524.pub3.

3. Ilyas M, Afzal S, Ahmad J, Alghamdi S, Khurram M. The Resurgence of Measles Infection and its Associated Complications in Early Childhood at a Tertiary Care Hospital in Peshawar, Pakistan. Pol J Microbiol. 2020;69(2):1-8. doi: 10.33073/pjm-2020-020.

4. Duke T, Mgone CS. Measles: not just another viral exanthem. Lancet. 2003;361(9359):763-73. doi: 10.1016/S0140-6736(03)12661-X.

5. Moss WJ, Griffin DE. Measles. Lancet. 2012;379(9811):153-64. doi: 10.1016/S0140-6736(10)62352-5.

6. Robbins FC. Measles: clinical features. Pathogenesis, pathology and complications. Am J Dis Child. 1962; 103:266-73. doi: 10.1001/ archpedi.1962.02080020278018.

7. Hall V, Banerjee E, Kenyon C, Strain A, Griffith J, Como-Sabetti K, Heath J, Bahta L, Martin K, McMahon M, Johnson D, Roddy M, Dunn D, Ehresmann K. Measles Outbreak - Minnesota April-May 2017. MMWR Morb Mortal Wkly Rep. 2017;66(27):713-717. doi: 10.15585/mmwr.mm6627a1.

8. Piccirilli G, Lazzarotto T, ChiereghinA, Serra L, Gabrielli L, Lanari M. Spotlight on measles in Italy: why outbreaks of a vaccine-preventable infection continue in the 21st century. Expert Rev Anti Infect Ther. 2015;13(3):355-62. doi: 10.1586/14787210.2015.1003808.

9. Sá Machado R, Perez Duque M, Almeida S, Cruz I, Sottomayor A, Almeida I, R Oliveira J, Antunes D. Measles outbreak in a tertiary level hospital, Porto, Portugal, 2018: challenges in the post-elimination era. Euro Surveill. 2018;23(20):18-00224. doi: 10.2807/15607917.ES.2018.23.20.18-00224.

10. WHO warns that progress towards eliminating measles has stalled [http:// www.who.int/mediacentre/news/releases/2014/eliminatingmeasles/en/. Accessed 5 April 2017.

11. Patel M.K., Gacic-Dobo M., Strebel P.M., Dabbagh A., Mulders M.N., Okwo-Bele J., Dumolard L., Rota P.A., Kretsinger K., Goodson J.L. Progress toward regional measles elimination-Worldwide, 2000-2015. Morb. Mortal. Wkly. Rep. 2016;65:1228-1233. doi: 10.15585/mmwr.mm6544a6.

12. World Health Organization Regional Office for Europe. EpiBrief. 2016;1:1-11. Available at.

13. Seither R, Calhoun K, Knighton CL, Mellerson J, Meador S, Tippins A, Greby SM, Dietz V. Vaccination Coverage Among Children in Kindergarten - United States, 2014-15 School Year. MMWR Morb Mortal Wkly Rep. 2015;64(33):897-904. doi: 10.15585/mmwr. mm6433a2.

14. Orenstein WA, Hinman A, Nkowane B, Olive JM, Reingold A. Measles and Rubella Global Strategic Plan $2012-2020$ midterm review. Vaccine. 2018;36 Suppl 1:A1-A34. doi: 10.1016/j.vaccine.2017.09.026.

15. Abeev A, Zhylkibayev A, Kamalova D, Kusheva N, Nusupbaeva G, Tleumbetova N, Smagul M, Beissenova S, Aubakirova S, Kassenova Z, Demessinova B, Amanbayev A, Ramankulov Y, Shevtsov A. Epidemiological Outbreaks of Measles Virus in Kazakhstan during 2015. Jpn J Infect Dis. 2018;71(5):354-359. doi: 10.7883/yoken.JJID.2017.565.

16. Dabbagh A, Laws RL, Steulet C, Dumolard L, Mulders MN, Kretsinger K, Alexander JP, Rota PA, Goodson JL. Progress Toward Regional Measles Elimination - Worldwide, 2000-2017. MMWR Morb Mortal Wkly Rep. 2018;67(47):1323-1329. doi: 10.15585/ mmwr.mm6747a6. 
17. Thornton J. Measles cases in Europe tripled from 2017 to 2018. BMJ. 2019;364:1634. doi: 10.1136/bmj.1634.

18. Griffin DE, Moss WJ. Measles. Lancet. 2012;379(9811):153-64. doi: 10.1016/S0140-6736(10)62352-5.

19. Thornton J. Measles cases in Europe tripled from 2017 to 2018. BMJ. 2019;364:1634. doi: 10.1136/bmj.1634.

20. Dardis MR. A review of measles. J Sch Nurs. 2012;28(1):9-12. doi: 10.1177/1059840511429004.

21. Bentley J, Rouse J, Pinfield J. Measles: pathology, management and public health issues. Nurs Stand. 2014;28(38):51-8. doi: 10.7748/ ns.28.38.51.e8765.

22. Rota PA, Moss WJ, Takeda M, de Swart RL, Thompson KM, Goodson JL. Measles. Nat Rev Dis Primers. 2016;2:16049. doi: 10.1038/ nrdp.2016.49.

23. Shanks GD, Hu Z, Waller M, Lee SE, Terfa D, Howard A, van Heyningen E, Brundage JF. Measles epidemics of variable lethality in the early 20th century. Am J Epidemiol. 2014;179(4):413-22. doi: 10.1093/aje/kwt282.

24. Genetic Analysis of Measles Viruses. https://www.cdc.gov/measles/lab-tools/genetic-analysis.html

25. Bernstein HH, Bocchini JA Jr; Committee on infectious diseases. The Need to Optimize Adolescent Immunization. Pediatrics. 2017;139(3):e20164186. doi: 10.1542/peds.2016-4186.

26. Klein SL, Marriott I, Fish EN. Sex-based differences in immune function and responses to vaccination. Trans R Soc Trop Med Hyg. 2015;109(1):9-15. doi: 10.1093/trstmh/tru167.

27. Rouse J, Bentley J. Pinfield J. Measles: pathology, management and public health issues. Nurs Stand. 2014;28(38):51-8. doi: 10.7748/ ns.28.38.51.e8765.

28. Huiming Y, Chaomin W, Meng M. Vitamin A for treating measles in children. Cochrane Database Syst Rev. 2005;2005(4):CD001479. doi: 10.1002/14651858.CD001479.pub3.

29. Bello S, Meremikwu MM, Ejemot-Nwadiaro RI, Oduwole O. Routine vitamin A supplementation for the prevention of blindness due to measles infection in children. Cochrane Database Syst Rev. 2016;(8):CD007719. doi: 10.1002/14651858.CD007719.pub4.

30. Bichon A, Aubry C, Benarous L, Drouet H, Zandotti C, Parola P, Lagier JC. Case report: Ribavirin and vitamin A in a severe case of measles. Medicine (Baltimore). 2017;96(50):e9154. doi: 10.1097/MD.0000000000009154.

31. Imdad A, Mayo-Wilson E, Herzer K, Bhutta ZA. Vitamin A supplementation for preventing morbidity and mortality in children from six months to five years of age. Cochrane Database Syst Rev. 2017;3(3):CD008524. doi: 10.1002/14651858.CD008524.pub3.

32. Kobaidze K, Wallace G. Forgotten but Not Gone: Update on Measles Infection for Hospitalists. J Hosp Med. 2017;12(6):472-476. doi: $10.12788 / \mathrm{jhm} .2752$.

33. Piccirilli G, Lazzarotto T, Chiereghin A, Serra L, Gabrielli L, Lanari M. Spotlight on measles in Italy: why outbreaks of a vaccinepreventable infection continue in the 21st century. Expert Rev Anti Infect Ther. 2015;13(3):355-62. doi: 10.1586/14787210.2015.1003808.

34. Klein NP, Zerbo O, Goddard K, Wang W, Fohner AE, Wiesner A, Shokoohi V, Coller J, Bok K, Gans HA. Genetic associations with a fever after measles-containing vaccines. Hum Vaccin Immunother. 2021;17(6):1763-1769. doi: 10.1080/21645515.2020.1849520. Epub 2020 Dec 22.

35. Bester JC. Measles and Measles Vaccination:AReview. JAMAPediatr. 2016;170(12):1209-1215. doi: 10.1001/jamapediatrics.2016.1787.

36. Lindberg C, Lanzi M, Lindberg K. Measles: Still a Significant Health Threat. MCN Am J Matern Child Nurs. 2015;40(5):298-305; quiz E21-2. doi: 10.1097/NMC.0000000000000162.

37. Sood SB, Suthar K, Martin K, Mather K. Vaccine-associated measles in an immunocompetent child. Clin Case Rep. 2017;5(11):17651767. doi: 10.1002/ccr3.1174.

38. Kumar D, Sabella C. Measles: Back again. Cleve Clin J Med. 2016;83(5):340-4. doi: 10.3949/ccjm.83a.15039.

39. Caldararo S. Measles. Pediatr Rev. 2007;28(9):352-4. doi: 10.1542/pir.28-9-352.

40. Moss WJ. Measles. Lancet. 2017;390(10111):2490-2502. doi: 10.1016/S0140-6736(17)31463-0.

41. Piccirilli G, Lazzarotto T, Chiereghin A, Serra L, Gabrielli L, Lanari M. Spotlight on measles in Italy: why outbreaks of a vaccinepreventable infection continue in the 21st century. Expert Rev Anti Infect Ther. 2015;13(3):355-62. doi: 10.1586/14787210.2015.1003808.

42. 42. Gadler T, Martinez N, Ogg-Gress J. Recognizing Measles, Mumps, and Rubella in the Emergency Department. Adv Emerg Nurs J. 2018;40(2):110-118. doi: 10.1097/TME.0000000000000190.

43. 43. Imdad A, Mayo-Wilson E, Herzer K, Bhutta ZA. Vitamin A supplementation for preventing morbidity and mortality in children from six months to five years of age. Cochrane Database Syst Rev. 2017;3(3):CD008524. doi: 10.1002/14651858.CD008524.pub3.

44. Dardis MR. A review of measles. J Sch Nurs. 2012;28(1):9-12. doi: 10.1177/1059840511429004.

45. Chovatiya R, Silverberg JI. Inpatient morbidity and mortality of measles in the United States. PLoS One. 2020;15(4):e0231329. doi: 10.1371/journal.pone.0231329.

46. Roose J, Rohaert C, Jadoul A, Fölster-Holst R, van Gysel D. Modified Measles: A Diagnostic Challenge. Acta Derm Venereol. 2018;98(2):289-290. doi: 10.2340/00015555-2825.

47. Bhatt JM, Huoh KC. Otolaryngological manifestations of Measles (Rubeola): A case report and brief review. Laryngoscope. 2016;126(6):1481-1483. doi: 10.1002/lary.25549.

48. Lai WS, Lin YY, Wang CH, Chen HC. Measles: A missed cause of acute tonsillitis. Ear Nose Throat J. 2017;96(10-11):E54-E55. doi: 10.1177/0145561317096010-1111.

49. Colombo I, Forapani E, Spreafico C, Capraro C, Santilli I. Acute myelitis as presentation of a reemerging disease: measles. Neurol Sci. 2018;39(9):1617-1619. doi: 10.1007/s10072-018-3416-0.

50. Fisher DL, Defres S, Solomon T. Measles-induced encephalitis. QJM. 2015;108(3):177-82. doi: 10.1093/qjmed/hcu113

51. Garg RK, Malhotra HS, Rizvi I, Kumar N, Jain A. An unusual case of acute encephalitic syndrome: Is it acute measles encephalitis or subacute sclerosing panencephalitis? Neurol India. 2017;65(6):1333-1344. doi: 10.4103/0028-3886.217942.

52. Campos-Outcalt D. Measles: Why it's still a threat. J Fam Pract. 2017;66(7):446-449.

53. MacFadden DR, Gold WL. Measles. CMAJ. 2014;186(6):450. doi: 10.1503/cmaj.130958.

54. McCarthy M. US sees first measles death in 12 years. BMJ. 2015;351:h3653. doi: 10.1136/bmj.h3653.

55. Wyplosz B, Lafarge M, Escaut L, Stern JB. Fatal measles pneumonitis during Hodgkin's lymphoma. BMJ Case Rep. 2013;2013:bcr2013200252. doi: 10.1136/bcr-2013-200252. 
56. Update of the nomenclature for describing the genetic characteristics of wild-type measles viruses: New genotypes and reference strains. Wkly. Epidemiol. Rec. 2003; 78:229-232.

57. Kessler, J.R.; Kremer, J.R.; Shulga, S.V.; Tikhonova, N.T.; Santibanez, S.; Mankertz, A.; Semeiko, G.V.; Samoilovich, E.O.; Tamfum, J.J.M.; Pukuta, E.; et al. Revealing new measles virus transmission routes by use of sequence analysis of phosphoprotein and hemagglutinin genes. J. Clin. Microbiol. 2011; 49:677-683. doi: 10.1128/JCM.01703-10.

58. Gardy, J.L.; Naus, M.; Amlani, A.; Chung, W.; Kim, H.; Tan, M.; Severini, A.; Krajden, M.; Puddicombe, D.; Sahni, V.; et al. Wholegenome sequencing of measles virus genotypes H1 and D8 during outbreaks of infection following the 2010 Olympic winter games reveals viral transmission routes. J. Infect. Dis. 2015; 212:1574-1578. doi: 10.1093/infdis/jiv271.

59. Bichon A, Aubry C, Benarous L, Drouet H, Zandotti C, Parola P, Lagier JC. Case report: Ribavirin and vitamin A in a severe case of measles. Medicine (Baltimore). 2017;96(50):e9154. doi: 10.1097/MD.0000000000009154.

60. Paules CI, Marston HD, Fauci AS. Measles in 2019 - Going Backward. N Engl J Med. 2019;380(23):2185-2187. doi: 10.1056/ NEJMp1905099.

61. Rota PA, Bankamp B. Whole-Genome Sequencing During Measles Outbreaks. J Infect Dis. 2015;212(10):1529-30. doi: 10.1093/ infdis/jiv272. 